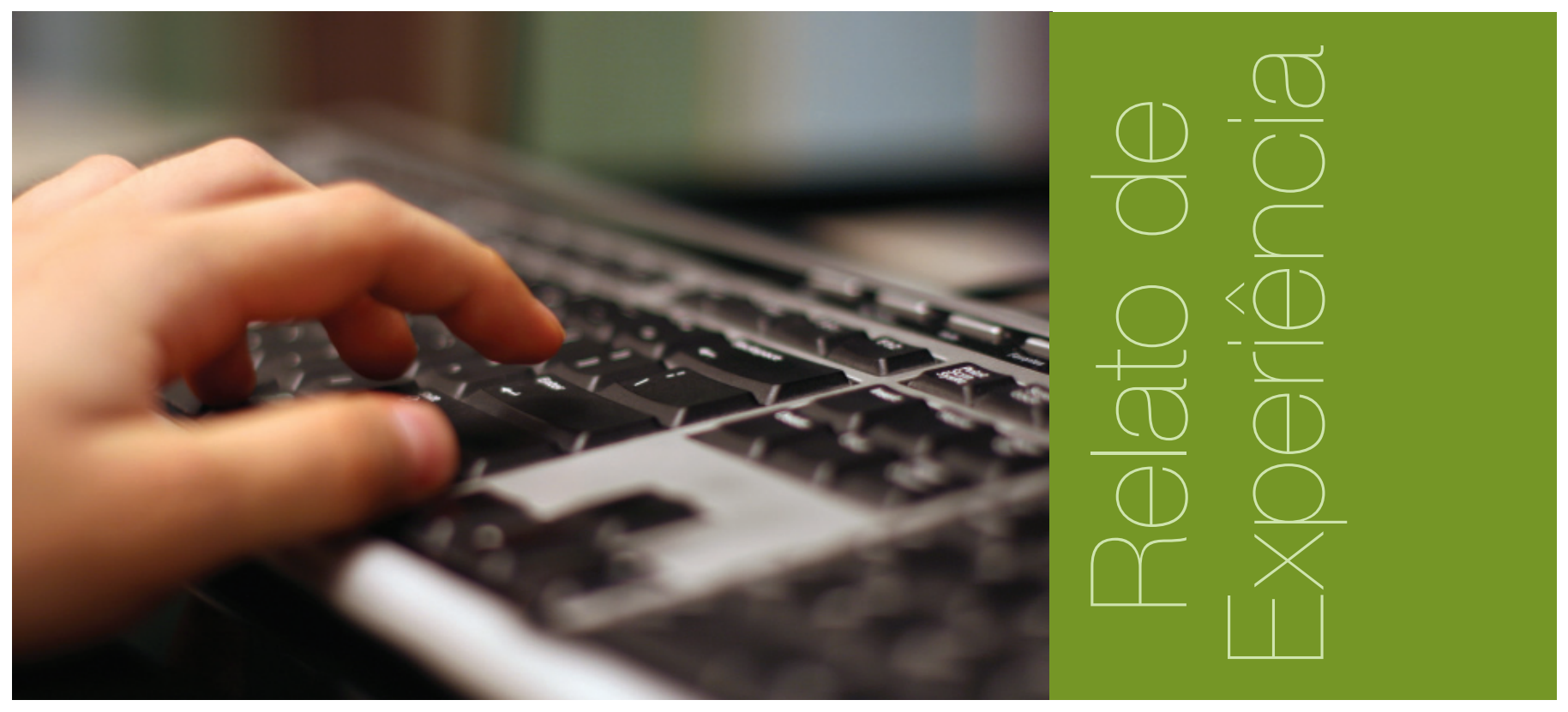

\title{
Informática básica e apoio pedagógico para menores de uma casa-lar em Videira/SC
}

\author{
Denise Danielli Pagno1 - denise@ifc-videira.edu.br \\ Joana Ester Gonçalves Lins² - joananalins@gmail.com \\ Mikelen Vicelli ${ }^{3}$ mikelen.vicelli@gmail.com
}

\section{RESUMO}

Este projeto de extensão consistiu em uma experiência de formação desenvolvida com crianças e adolescentes de uma Casa-lar. A iniciativa surgiu após a narrativa sobre as dificuldades de aprendizagem dos internos por uma pedagoga que atuava como educadora/cuidadora e participou de um dos cursos realizados no IFC. 0 objetivo principal foi oferecer diversos recursos e possibilidades que contribuiriam com o êxito na aprendizagem dos conteúdos escolares pelos menores abrigados.

\section{PALAVRAS-CHAVE}

Informática Básica, Dificuldades de Aprendizagem, Casa-lar.

\section{ABSTRACT}

This extension project consisted of a training experience developed with children and adolescents in a home-home. The initiative came after the story about the internal learning difficulties by an educator who served as an educator / caregiver and attended one of the courses held at IFC. The main objective was to offer various features and possibilities that contribute to the success in learning of school subjects by lower housed.

\footnotetext{
1 Técnica em Assuntos Educacionais do Instituto Federal Catarinense Campus Videira/SC e Mestre em Educação pela Universidade do Oeste de Santa Catarina (UNOESC).

2 Bolsista do Projeto de Extensão e Acadêmica do Curso de Bacharel em Ciência da Computação do Instituto Federal Catarinense Campus de Videira/SC.

3 Acadêmica do Curso de Bacharel em Ciência da Computação do Instituto Federal Catarinense Campus de Videira/SC e colaboradora deste projeto.
} 


\section{KEYWORDS}

Basic Computer, Learning Disabilities, Abandoned Children.

\section{Relato de experiência}

Este trabalho foi realizado nas salas de aula, nos laboratórios de informática e na área de convivência do Instituto Federal Catarinense, nas quartas-feiras no período vespertino compreendido entre agosto e novembro de 2014. As crianças se deslocavam da casa-lar até 0 IFC e permaneciam na instituição ao longo da tarde.

Foram seis meninos com idade entre 12 e 16 anos e quatro meninas com idade entre 14 e 16 anos. Entre eles encontrava-se uma menina com 15 anos que apresentava deficiência intelectual e estava matriculada na quinta série do ensino fundamental. Este dado nos foi repassado pela assistência social do município de Videira-SC. Esta menina, que vamos chamar de Mônica ${ }^{4}$, relatou que apresentava muitas dificuldades na escola.

Por meio da aplicação de alguns exercícios de Língua Portuguesa e Matemática diferenciados e de acordo com a faixa etária e a idade escolar dos estudantes, foram constatadas diversas dificuldades de aprendizagem e déficit em conhecimentos básicos em todas as crianças e jovens nas áreas das linguagens e da matemática.

Constataram-se cadernos incompletos, ausência de organização e de realização das tarefas diárias e avaliações com baixo rendimento.

Esta é uma pesquisa participante baseada nos estudos de Brandão (1981). Segundo o autor, a finalidade da pesquisa-ação é a de favorecer a aquisição de um conhecimento e de uma consciência crítica do processo de transformação pelo grupo que está vivendo este processo, para que ele possa assumir, de forma cada vez mais lúcida e autônoma, seu papel de protagonista e autor social.

Na tarde de 13 de agosto, os participantes foram recepcionados no Campus do IFC Videira. Aconteceu uma acolhida com uma dinâmica de grupo de apresentação, onde as cursistas orientandas e orientadora deste projeto conheceram e se apresentaram aos jovens. Depois da dinâmica de apresentação, os estudantes responderam a um exercício com atividades básicas de matemática e de linguagem.

Os resultados mostraram dificuldades em relação à aprendizagem dos conteúdos escolares. Entre eles, havia uma estudante com deficiência intelectual e que estava habituada com a mediação da professora para desenvolver o seu raciocínio. Durante a execução de todas as etapas do trabalho, a maioria dos estudantes apresentou dificuldades em colocar os resultados no papel no exercício escrito, entretanto, no jogo desenvolvido no laboratório de informática, os estudantes demonstraram entendimento, compreensão e raciocínio ágeis. Constatamos expectativa e interesse dos jovens na realização dos trabalhos ao longo da tarde.

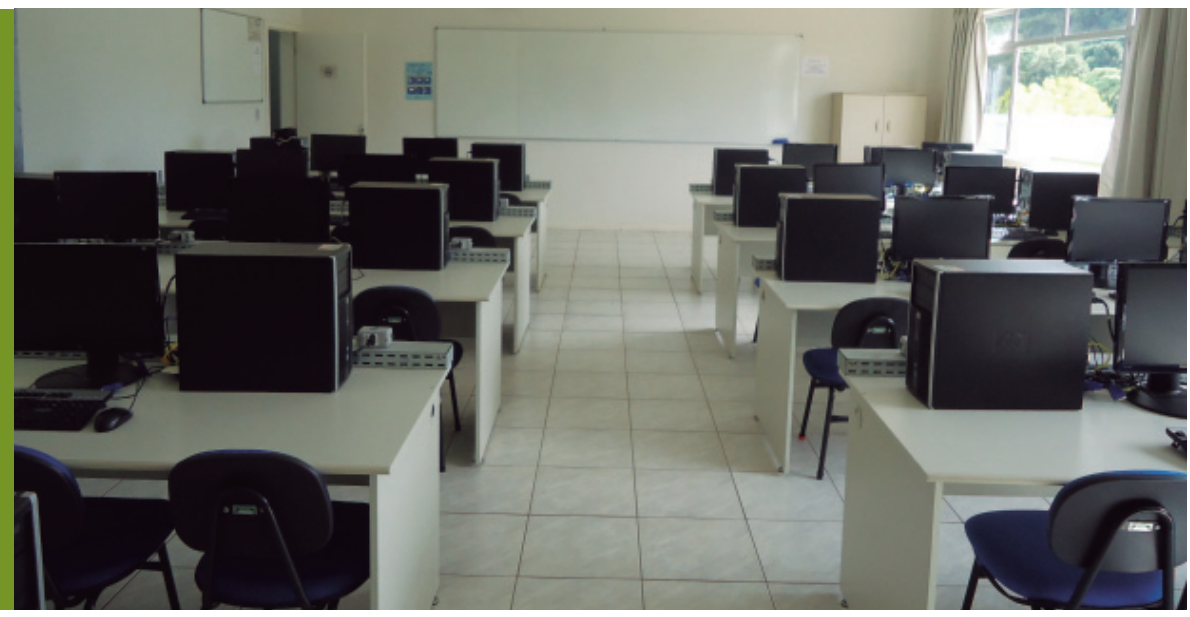

4 Todos os nomes das crianças que participaram deste trabalham foram substituídos de modo a preservar a identidade dos participantes. Da mesma forma, nenhuma fotografia foi publicada para preservar a imagem dos menores. 
São dificuldades na leitura, na escrita, com os cálculos matemáticos, déficits relacionados à atenção e a memória e as dificuldades para concentrar-se que se encontram entre os diversos motivos que resultam em reprovação e abandono escolar em idade anterior à estabelecida. Numerosas pesquisas apontam que a privação emocional na infância, onde os menores que não contaram com nenhuma figura de apego tendem a apresentar problemas emocionais, sociais, escolares e de conduta (LÓPES, 2004).

Foi trabalhado com fundamentos matemáticos com o material dourado e as representações de unidade, dezena e centena estimulando as crianças a manusear e a utilizar o material. Os estudantes jogaram diversos jogos de tabuleiro por meio do qual realizaram cálculos matemáticos para passar de fase e chegar ao final. Também desenvolveram operações de multiplicação com o material dourado. No laboratório de informática foi ensinado sobre o Paint e 0 Bloco de Notas. Alguns comandos básicos como o ctrl $+\mathrm{C}=$ copiar, ctrl $+\mathrm{V}=$ colar, ctrl $+\mathrm{Z}=$ desfaz e volta ao início e ESC=fecha programas e diminui a tela foram trabalhados com a turma. No dia 10 de setembro, a tabuada do algarismo dois ao nove foi demonstrada por meio de uma dinâmica com o material dourado e com copos plásticos, onde os estudantes preenchiam com o produto das multiplicações o copo correspondente a multiplicação em um cartaz. Na primeira etapa, foram preenchidos todos os copos correspondentes aos múltiplos com as unidades e dezenas do material dourado. Depois, os estudantes tinham que preencher sozinhos. Por último, foi tomada a tabuada dos estudantes e um deles, que acertou todas ganhou como lembrança e incentivo uma caixa de lápis de cor com doze cores, um lápis preto e uma borracha. No laboratório de informática, os alunos fizeram uma atividade no aplicativo para desenho e edição simples de imagem Paint, onde procuraram uma imagem no site de busca Google relacionada à computação, cortaram, copiaram e colaram a imagem no aplicativo utilizando comandos de teclado, fazendo um desenho na imagem já cortada.

Foi trabalhado um aplicativo chamado Word Pad, onde as crianças desenvolveram textos, modificaram a fonte, tamanho e cor de seus textos, inseriram imagens e desenhos. Depois foi mostrado o Libre Office Writer e as crianças não demonstraram dificuldade. No dia primeiro de outubro foi trabalhado o Libre Office Impress, um aplicativo onde se é possivel fazer slides. Os estudantes terminaram os slides e socializaram com os outros por meio de uma apresentação no projetor multimídia. As crianças acessaram um software educativo de matemática que pedia resultados de operações matemáticas de multiplicação. No dia 29 de outubro foi trabalhado com o programa Libre Office Calc. Os estudantes aprenderam a elaborar planilhas e gráficos. Não aprenderam sobre tabelas nas escolas e por este motivo foi um pouco difícil mostrar para que elas serviam e como eles poderiam usá-las, mas ainda assim, eles compreenderam 0 básico. Foi encaminhado um exercício de elaboração de tabela e gráfico que os estudantes desempenharam com êxito.

Essa ligação e abertura do Instituto Federal para os menores da casa-lar fortalece 0 desenvolvimento humano, social, afetivo e cultural dos meninas e meninas. Vigotski afirma e confere destaque para a importância da interação social no desenvolvimento infantil. Segundo ele, o desenvolvimento mental humano depende das formas sociais da vida humana (REG0, 2014).

De modo geral, podemos dizer que as crianças e jovens gostaram do trabalho e da oportunidade que tiveram de aprender e de estudar no Instituto Federal. Com este projeto conheceram o Campus e alguns se interessaram em prestar o processo seletivo para ingressar nos cursos. Esse resultado foi obtido por meio de uma conversa onde os mesmos se sentiram à vontade para avaliar o trabalho do qual participaram. A estudante com deficiência intelectual pedia ajuda constantemente e apontava a sua dificuldade. No desenvolver das atividades, mostrava-se comprometida e em sintonia com o que estava sendo trabalhado.

Observou-se principalmente que ao longo do projeto, atividades que envolviam graus de complexidade e de raciocínio lógico eram desenvolvidas com maior agilidade e o conhecimento, tanto nas áreas da matemática e das linguagens quanto na área da informática era assimilado sem a dificuldade que era encontrada no começo. Com isso, o que se conclui é que entre os adolescentes da casa lar há uma dupla carência: a afetiva de origem familiar e a escolar e uma interfere na outra intrinsecamente. 0 desafio é trabalhar com esta necessidade que vai além da aprendizagem. 


\section{Referências}

BRANDÃo, Carlos Rodrigues. Pesquisa Participante. São Paulo: Editora Brasiliense, 1981.

LÓPEZ, Félix. Problemas Afetivos e de Conduta na Sala de Aula. In: COLL,César. MARQUESI, Álvaro. PALACIOS, Jésus. Desenvolvimento Psicológico e Educação, Transtornos de Desenvolvimento e Necessidades Educativas Especiais, trad. Fátima Murad. 2a ed. Porto Alegre, Artmed, 2004, p. 113-128.

REGO, Teresa Cristina. Vygotski: Uma Perspectiva Histórico-Cultural da Educação. Petrópolis: Vozes, 2014. 